Article

\title{
Phenols Removal from Hemicelluloses Pre-Hydrolysate by Laccase to Improve Butanol Production
}

\author{
Rosalie Allard-Massicotte ${ }^{1,2}$, Hassan Chadjaa ${ }^{1}$ and Mariya Marinova ${ }^{2,3, *}$ \\ 1 Centre National en Électrochimie et en Technologies Environnementales, Shawinigan, QC G9N 6V8, Canada; \\ rosalie.allard-massicotte@polymtl.ca (R.A.-M.); hchadjaa@collegeshawinigan.qc.ca (H.C.) \\ 2 Department of Chemical Engineering, Polytechnique Montréal, Montréal, QC H3T 1J4, Canada \\ 3 Department of Wood and Forest Sciences, Université Laval, 2405 rue de la Terrasse, \\ Québec, QC G1V 0A6, Canada \\ * Correspondence: mariya.marinova.1@ulaval.ca
}

Received: 9 May 2017; Accepted: 26 June 2017; Published: 30 June 2017

\begin{abstract}
Phenolic compounds are important inhibitors of the microorganisms used in the Acetone-Butanol-Ethanol (ABE) fermentation. The degradation of phenolic compounds in a wood pre-hydrolysate, a potential substrate for the production of ABE, was studied in this article. First, physicochemical methods for detoxification such as nanofiltration and flocculation were applied and the best combination was selected. With a flocculated sample, the concentration of phenolic compounds decreases from 1.20 to $0.28 \mathrm{~g} / \mathrm{L}$ with the addition of a solid laccase at optimum conditions, which is below the phenolic compounds limit of inhibition. This results in an increase in butanol production, more than double, compared to a pre-hydrolysate non-treated with laccase enzymes.
\end{abstract}

Keywords: phenolic compounds; detoxification; butanol; pre-hydrolysate; laccase enzymes

\section{Introduction}

The acetone-butanol-ethanol (ABE) fermentation was developed in the late 19th and the early 20th century and is one of the first fermentation processes adapted to a large scale. The main reason for this was the growing need of acetone for munitions factories during the two World Wars [1]. Today, the production of butanol and its derivatives is attractive for international markets [2]. In addition, butanol is a high-energy fuel, less corrosive than ethanol, and its derivatives are used for the production of latex, plasticizers and coatings [3]. Although ABE fermentation with Clostridium acetobutylicum has been well known, improvements are still being proposed to decrease the cost of substrate and the subsequent operating costs. In a previous work conducted by Ajao et al. [4,5], the detoxification of a wood pre-hydrolysate, obtained from a dissolving Kraft pulp mill, was conducted by filtration and flocculation, prior to ethanol production by fermentation.

In the current study, the pre-hydrolysate was used as a substrate to grow C. acetobutylicum and to produce butanol. During the pre-hydrolysis step, phenolic compounds which are lignin residues are generated [6,7]. They can damage the structure of the cell membrane and the ability of microorganisms to absorb sugars, which makes them very toxic for the ABE fermentation [8]. The reduction of the phenolic compounds concentration by flocculation was significant [4]; however, it was not sufficient to improve fermentation yield. The conventional treatment of the pre-hydrolysate cannot reduce the concentration of phenolic compounds below the inhibition limit, as set by Mechmech et al. [9].

In this work, the degradation of the phenolic compounds using solid and liquid laccase enzymes was investigated to complement the physicochemical treatment. Laccases are copper-containing enzymes and can oxidize several types of phenolic compounds [10-12]. The enzymatic degradation of 
phenolic compounds was investigated on aqueous solutions inspired by wastewater treatment [13-15]. These studies have been done with laccases or peroxydases, oxidative enzymes similar to the laccases. The method can significantly improve the degradation of phenolic compounds, thus reaching the thresholds that do not allow inhibition. There are two important aspects to understand the relevance of this work: the world population is concerned about the environment protection and the revalorization of resources can be an additional income for pulp and paper mills. The detoxification of lignocellulosic biomass by laccases was investigated to increase the quality of the substrate in ethanol production [16]. In the current study, it is shown that the degradation of the phenolic compounds prior to fermentation using laccases can increase the production of butanol from a wood pre-hydrolysate and improve the cost-effectiveness of the process. In North America, where the pulp and paper industry is under transformation, looking to implement innovative processes, it is important to maximize the reuse of resources in a biorefinery context [17].

\section{Materials and Methods}

\subsection{Microorganism, Culture Maintenance and Inoculum Preparation}

The culture preparation was performed as described by Mechmech et al. [9]. C. acetobutylicum ATCC 824 was obtained from the American Type Culture Collection (ATCC) and was cultured in sterilized Reinforced Clostridium Medium (RCM), its composition being (in g/L): tryptose 10, beef extract 10 , glucose 5 , yeast extract 3 , soluble starch 0.5 , sodium chloride 5 , l-cysteine- $\mathrm{HCl} 0.5$. The culture was kept under anaerobic conditions at $37^{\circ} \mathrm{C}$ for $18-22 \mathrm{~h}$, with shaking at $110 \mathrm{rpm}$, until an Optical Density $\left(\mathrm{OD}_{600}\right)$ of $1.9-2$ was obtained. Glycerol $50 \% v / v$ was added to the bacterial culture to obtain a final concentration of $25 \%$ and the stock culture was immediately frozen at $-80{ }^{\circ} \mathrm{C}$ until use. For complete anaerobic conditions, a drop of sodium sulfide nonahydrate was added in a cryogenic tube.

The inoculum for ABE fermentation was prepared in a RCM medium. The medium was first boiled and then purged with a gas mixture of $80 \% \mathrm{~N} 2$ and $20 \% \mathrm{CO} 2$ to remove oxygen from the culture media. The culture was inoculated to a proportion of $1 / 2000$ with stock culture. Culture conditions were identical to those of the stock culture. Inoculum was ready to be inoculated at an OD600 between 0.6 and 0.9 .

\subsection{Fermentation Medium}

The fermentations experiments were carried out in a complex fermentation medium. The medium was composed of $60 \mathrm{~g} / \mathrm{L}$ of xylose and resazurin $0.001 \%$ base. Before sterilization, the base was first boiled and then purged with a gas mixture of $80 \% \mathrm{~N}_{2}$ and $20 \% \mathrm{CO}_{2}$ during $5 \mathrm{~min}$. After sterilization, a purged sterile solution of $200 \mathrm{~g} / \mathrm{L}$ of yeast extract was added in a ratio of $1 / 40$. A filtered mixture with $\mathrm{KH}_{2} \mathrm{PO}_{4} 50 \mathrm{~g} / \mathrm{L}, \mathrm{K}_{2} \mathrm{HPO}_{4} 50 \mathrm{~g} / \mathrm{L}$, ammonium acetate $220 \mathrm{~g} / \mathrm{L}$, para-aminobenzoic acid $0.1 \mathrm{~g} / \mathrm{L}$, thiamin $0.1 \mathrm{~g} / \mathrm{L}$, biotin $0.001 \mathrm{~g} / \mathrm{L}, \mathrm{MgSO}_{4} \cdot 7 \mathrm{H}_{2} \mathrm{O}, 20 \mathrm{~g} / \mathrm{L}, \mathrm{MnSO}_{4} \cdot \mathrm{H}_{2} \mathrm{O} 1 \mathrm{~g} / \mathrm{L}, \mathrm{FeSO}_{4} \cdot 7 \mathrm{H}_{2} \mathrm{O} 1 \mathrm{~g} / \mathrm{L}$ and $\mathrm{NaCl} 1 \mathrm{~g} / \mathrm{L}$ was added in a ratio of $1 / 100$. In some experiments, a phenolic compound was added to the xylose solution to maintain a specific concentration. Screw capped Schott bottles of $250 \mathrm{~mL}$ were filled with $200 \mathrm{~mL}$ of complete culture media and used for anaerobic fermentation. The culture media for the hydrolysate test consists of $195 \mathrm{~mL}$ of treated hydrolysate and $5 \mathrm{~mL}$ of yeast extract. Xylose $(60 \mathrm{~g} / \mathrm{L})$ was added in order to compare with the control solution. Before inoculation with $10 \mathrm{~mL}$ of inoculums, the bottles were slightly open in anaerobic jars containing Gas Pak envelopes (BD Gas Pak ${ }^{\mathrm{TM}}$ EZ Anaerobe Container System, Franklin Lakes, NJ, USA) with indicators (BD BBL ${ }^{\mathrm{TM}}$ Dry Anaerobic Indicator Strips, Franklin Lakes, NJ, USA) for $48 \mathrm{~h}$ to create perfect anaerobic conditions in the mixtures. If necessary, a solution containing $5 \% p / v$ of $\mathrm{Na}_{2} \mathrm{~S} \cdot 9 \mathrm{H}_{2} \mathrm{O}$ was added in a ratio of $1 / 400$ to eliminate the traces of oxygen. After inoculation, the cultures were incubated at $37^{\circ} \mathrm{C}, 110 \mathrm{rpm}$ and with a $\mathrm{pH}$ control. During fermentation, $5 \mathrm{~mL}$ samples were periodically withdrawn to analyze $\mathrm{OD}_{600}$, residual xylose and alcohols. All fermentation experiments were performed in duplicate. 


\subsection{Analytical Methods}

Spectrometer (Pharmacia Biotech Novaspec ${ }^{\circledR} \mathrm{II}$, Piscataway, NJ, USA) was used to monitor the growth of $C$. acetobutylicum and to determine the total phenols concentration with the Folin-Ciocalteu reagent method [18].

Gas chromatograph (GC 7890A, Agilent Technologies, Santa Clara, CA, USA) w ith an OV 624 capillary column and a flame ionization detector $\left(\mathrm{H}_{2}\right.$ flow rate: $30 \mathrm{~mL} / \mathrm{min}$; air flow rate: $\left.2.23 \mathrm{~mL} / \mathrm{min}\right)$ was used to measure butanol, acetone and ethanol concentrations in the fermentation medium after the inhibition test [9].

High performance liquid chromatography (HPLC Agilent Technology, Germany) was used to determinate the concentration of vanillin, catechol, syringaldehyde gallic acid and simple sugars. To measure phenols concentration, separation was made using a mixture of $15 \%$ acetonitrile and $85 \%$ phosphoric acid $10 \mathrm{mM}$ on a Nucleosil C18 $(150 \times 4.6 \mathrm{~mm})$ column with a diode array detector (DAD) at $313 \mathrm{~nm}$ and $280 \mathrm{~nm}$. Dilution for phenol analysis was performed in the same solvent to reach a maximum concentration of $500 \mathrm{ppm}$. To measure the simple sugar concentration, a refractive index detector and an EC Nucleodur $\mathrm{RP}_{-} \mathrm{NH}_{2}$ colum $(250 \mathrm{~mm} \times 4.6 \mathrm{~mm}, 5 \mu \mathrm{m})$ were used with a mixture of $75 \%$ acetonitrile and $25 \%$ deionized water as a solvent. A temperature of $40{ }^{\circ} \mathrm{C}$ and a flow rate of $1.5 \mathrm{~mL} / \mathrm{min}$ were applied for better separation [9]. Dilution for simple sugar analysis was performed in $50 \%$ acetonitrile and $50 \%$ deionized water to reach a maximum concentration of $10 \mathrm{~g} / \mathrm{L}$.

\subsection{Degradation with Laccase Enzymes}

For degradation assays, two types of laccase enzymes provided by industrial partners were used: a solid (or dehydrated) laccase and a liquid laccase. All degradation tests were performed in a test tube (14 mm diameter) with a $5 \mathrm{~mL}$ mixture composed of syringaldehyde, vanillin, catechol and gallic acid with the same concentrations. Total phenolic compounds concentrations of $2 \mathrm{~g} / \mathrm{L}, 4 \mathrm{~g} / \mathrm{L}$ and $6 \mathrm{~g} / \mathrm{L}$ were used. After $\mathrm{pH}$ adjustment with $4 \mathrm{M} \mathrm{NaOH}$, a fixed dose of laccase was added and the test tube was incubated for $7 \mathrm{~h}$ at the appropriate temperature and rotation at $180 \mathrm{rpm}$. When a large volume of flocculated hydrolysates was detoxified by laccase, an erlenmeyer was used with a ratio erlemeyer volume/flocculated hydrolysate volume of 2.5. A preliminary screening was done to determinate the optimal temperature and $\mathrm{pH}$ conditions for the subsequent experiments. The samples were analyzed once; however, occasional duplicate analyses were conducted to check the method used. Since the fermentation and enzyme degradation tests were performed, respectively, in duplicate and in triplicate, irregular results were easily detected and corrected.

\subsection{Preparation and Treatment of Hydrolysates}

Detoxification approaches described by Mechmech et al. [9] were first applied before the degradation of the phenolic compounds with laccase. To extract the hemicelluloses, a mixture of $60 \%$ aspen and $40 \%$ maple wood chips was treated with hot water and steam in a pilot digester at FPInnovations (Pointe-Claire, Québec, Canada). That pre-hydrolysate was forwarded to the Centre National en Électrochimie et en Technologies Environnementales (CNETE). Two different methods were applied to detoxify the pre-hydrolysate. First, pre-hydrolysate was filtered through the organic membrane NF270 (Molecular weight cut-off 200-400 Da), then hydrolyzed with $1.5 \% w / w$ sulfuric acid at $121{ }^{\circ} \mathrm{C}$ for $60 \mathrm{~min}$ to increase the monomeric sugars concentration. After these treatments, it was coagulated/flocculated. The $\mathrm{pH}$ was raised to 6.5 and ferric sulfate $\left(\mathrm{Fe}_{2}\left(\mathrm{SO}_{4}\right)_{3}\right)$ with a ratio $1 \mathrm{~g} \mathrm{Fe} / 1 \mathrm{~g}$ phenolic compound was added. Flocculation experiments were carried out in jar tests with an agitation of $150 \mathrm{rpm}$ for $10 \mathrm{~min}$., then $50 \mathrm{rpm}$ for $30 \mathrm{~min}$. In a second step, the same operations were performed, but without applying the nanomembrane filtration. 


\section{Results and Discussion}

\subsection{Optimization of the Degradation Conditions}

The screening of the solid and liquid laccase enzymes indicates that their efficiency is strongly affected by temperature and $\mathrm{pH}$. The results with a $2 \mathrm{~g} / \mathrm{L}$ synthetic solution containing syringaldehyde, vanillin, catechol and gallic acid in equal quantity have shown that the degradation of the phenolic compounds by laccases is optimal at a pH 8 and a temperature of $50{ }^{\circ} \mathrm{C}$ (Figures 1 and 2).

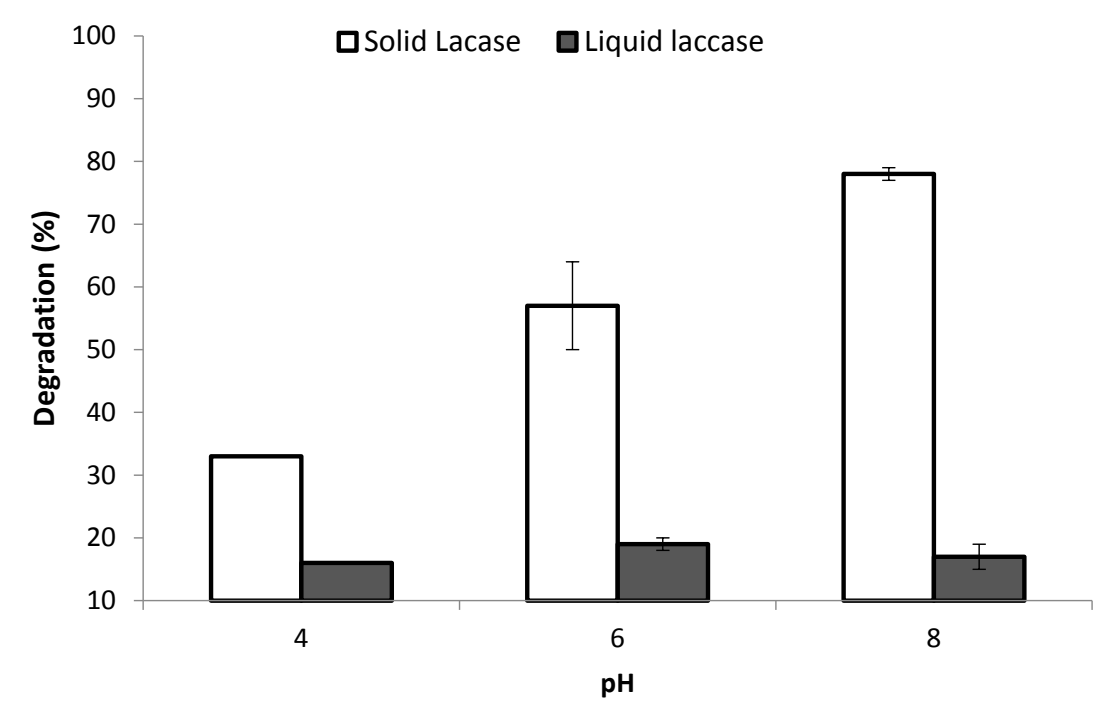

Figure 1. Degradation of phenolic compounds by laccase enzymes at different $\mathrm{pH}$.

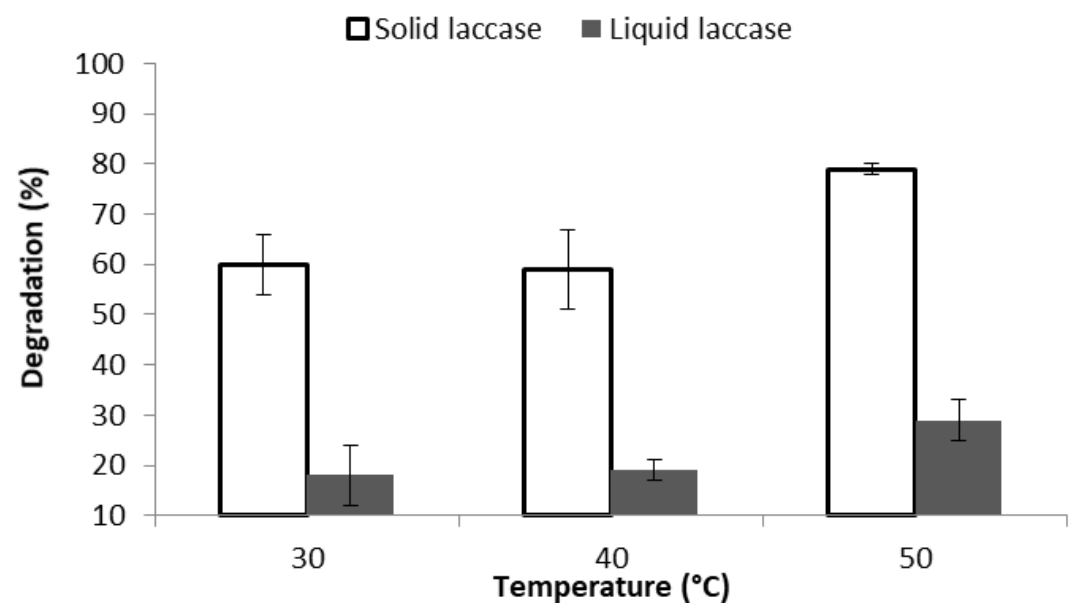

Figure 2. Degradation of phenolic compounds by laccase enzymes at different temperatures.

The optimal dose of the solid laccase is $100 \mathrm{mg}$ of enzyme/g of phenolic compounds. The results are similar when a dosage of $200 \mathrm{mg} / \mathrm{g}$ is used; however, for economic reasons, it is preferable to use $100 \mathrm{mg}$ enzyme/g of phenolic compounds (Figure 3). At optimal pH, temperature and enzyme dose, the degradation of the phenolic compounds by the solid laccase is $79 \%$. The most relevant parameters for this type of laccase are the $\mathrm{pH}$, the dose of laccase and the initial concentration of phenolic compounds $(p<0.01)$. Moreover, there is an interaction between the initial concentration of phenolic compounds and the dose of laccase; therefore, the dose of enzyme should be adjusted according to the initial concentration of phenolic compounds. An interaction regression coefficient of -0.24 between 
the dose of laccase and the initial concentration of phenolic compounds and a correlation value of 0.83 were calculated.

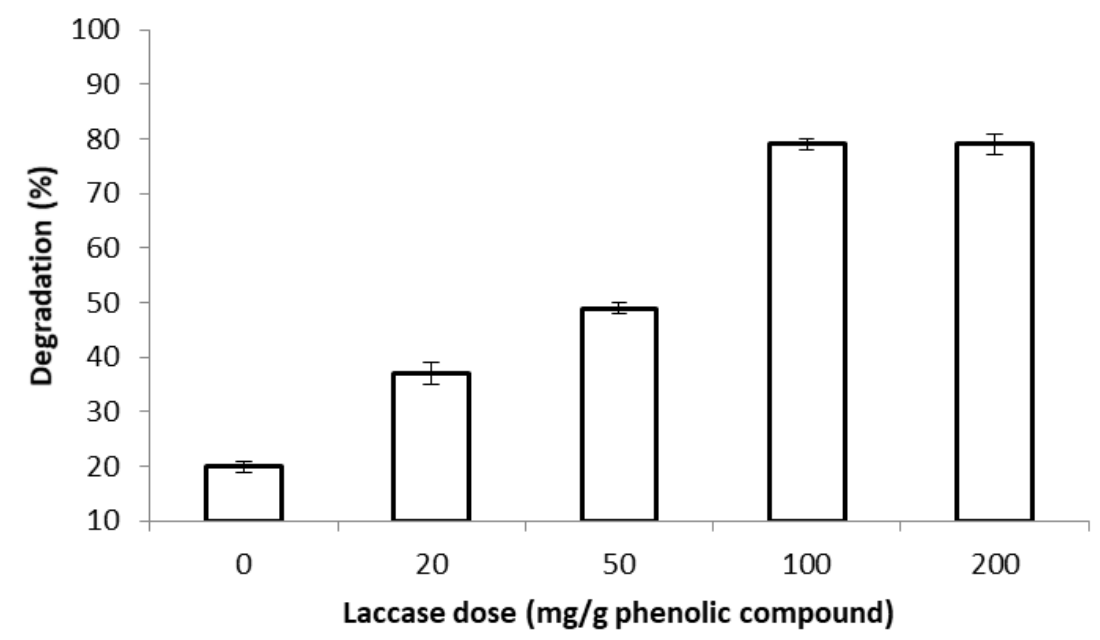

(a)

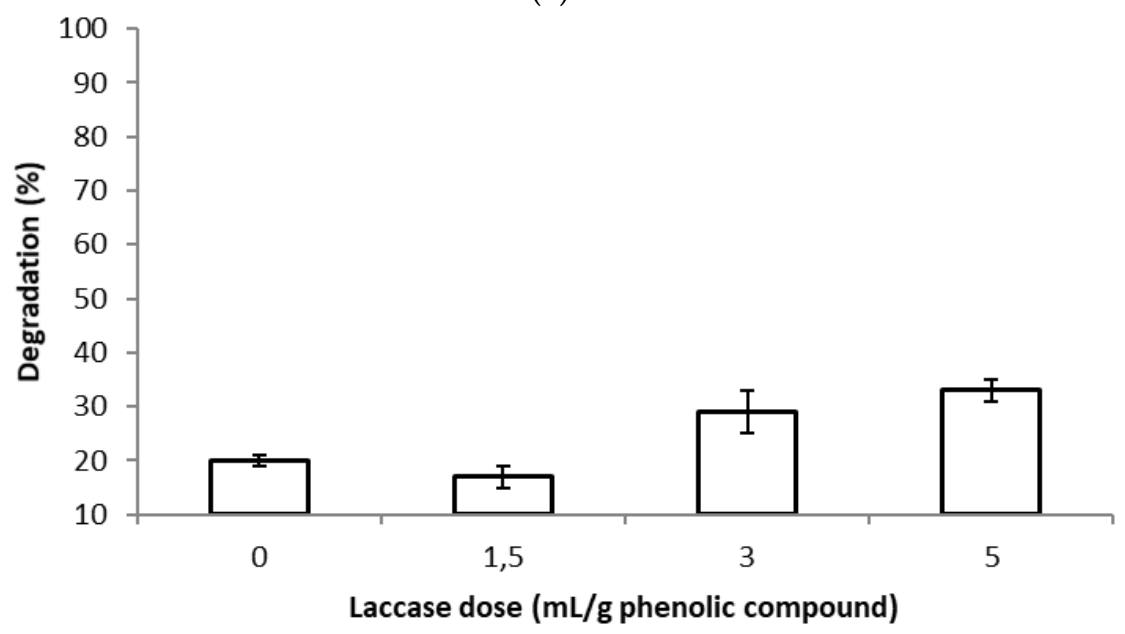

(b)

Figure 3. Degradation of phenolic compounds with different dose of laccase enzymes: (a) solid laccase; (b) liquid laccase.

The optimal dose for the liquid laccase is $5 \mathrm{~mL}$ enzyme/g of phenolic compounds (Figure 3). At optimal conditions, the degradation of the phenolic compounds by liquid laccase is $33 \%$. For economic reasons, it is suggested to use $3 \mathrm{~mL} / \mathrm{g}$ of phenolic compounds. When $3 \mathrm{~mL}$ of laccase enzyme are used, a degradation percentage of $29 \%$ is reached. It is important to mention that for the liquid laccase, the impact of the $\mathrm{pH}$ on the degradation efficiency is not significant $(p>0.05)$ and for practical reasons an initial $\mathrm{pH}$ of 8 was used. On the other hand, the temperature, the dose of laccase and the initial concentration of phenolic compounds are critical for the efficiency of the liquid laccase. A statistical analysis was performed and the results have shown a non-significant effect of $\mathrm{pH}$ and an important effect of the dose of laccase, the initial concentration of the phenolic compounds and the temperature. The regression coefficients for the three parameters were, respectively, $0.56,0.55$ and -0.49 , with a $p$-value $<0.01$.

According to the results on the degradation of phenolic compounds with laccases on various stages of the conventional detoxification presented in Section 3.4, the best results were obtained for a sample with $\mathrm{pH} 8$. It is important to point out that there is a link between the degradation time and 
the added dose of laccase $(p<0.01)$. In fact, the more the laccase dose was high, faster the degradation was. The control sample without laccase demonstrated a degradation of the phenolic compounds of $20 \%$ in time (Figure 3). Therefore, a part of the degradation was performed naturally and not by the laccases. The corresponding equation for the naturally occurring phenolic degradation in time was: $y=0.011 x^{2}-0.12 x+1.8$ with a correlation value of 0.77 . The degradation mainly occurs during the first hour, after that there was a stabilization of the phenolic compounds concentration.

\subsection{Influence of the Individual Phenolic Compounds}

The degradation of the phenolics is influenced by the type of individual phenolic compounds in the mixture. When the solid laccase was used, gallic acid was always degraded in the first two hours of incubation, followed by catechol which was entirely degraded too, then syringaldehyde and vanillin which were partially degraded at the end of incubation (Figure 4). Although it is not shown in the figure, it seems that there is a link with the temperature. When the temperature is lower $\left(40\right.$ and $30^{\circ} \mathrm{C}$ ), the degradation of gallic acid and catechol is accelerated, while the other phenolic compounds are not degraded. This implies a change in the conformation of the enzyme to make it suitable for the degradation of syringaldehyde and vanillin at high temperature. The conformation of the enzyme can explain that preference. Usually, when the number of alcohol group increases, the speed of degradation increases too. The laccases directly affect the alcohol groups by oxidation of a reducing substrate and the formation of a free radical [10]. The accessibility of these groups can also influence their oxidation and affect the degradation order. The nature of the individual phenolic compounds is therefore a critical factor for the degradation.

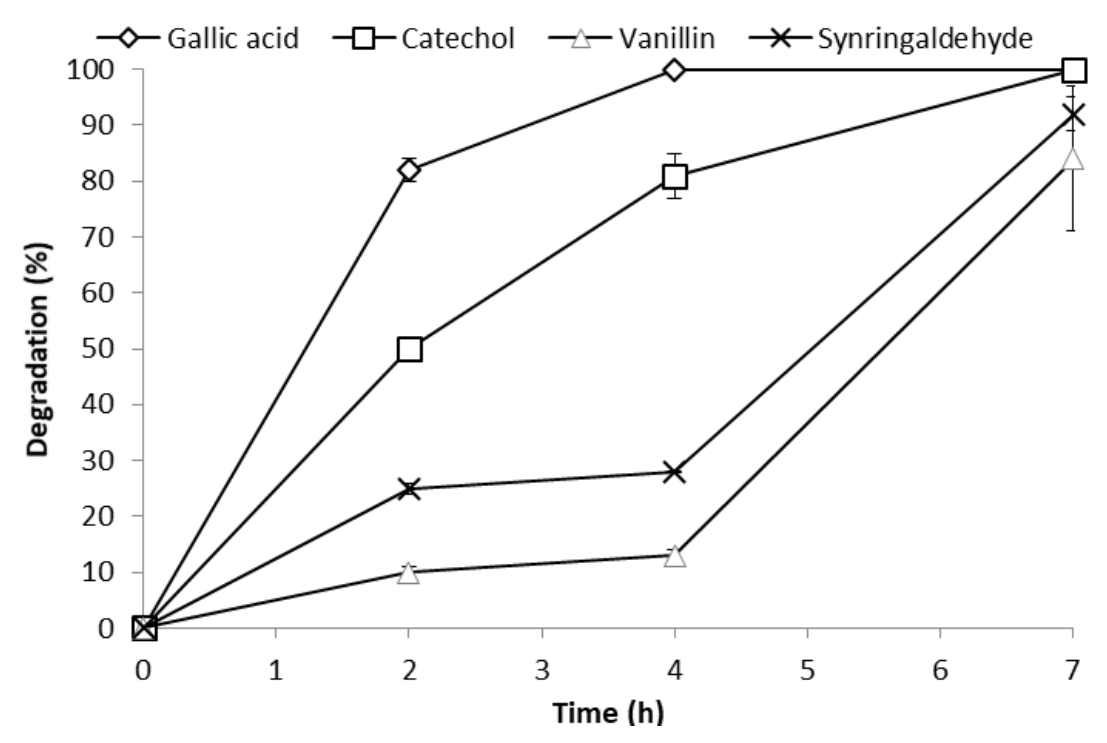

Figure 4. Degradation of the individual phenolic compounds using the solid laccase enzyme as a function of time.

The liquid laccase was efficient for gallic acid and syringladehyde degradation, but had a limited effect on vanillin and catechol, as shown in Figure 5. This confirms the importance of the type of phenolic compounds on the degradation by laccases. Gallic acid is degraded first, then syringaldehyde with $74 \%$ and $68 \%$ degradation, respectively. Only $35 \%$ and $29 \%$ of the catechol and vanillin, respectively, are degraded by the liquid laccase. These results are lower, compared to the solid laccase. 


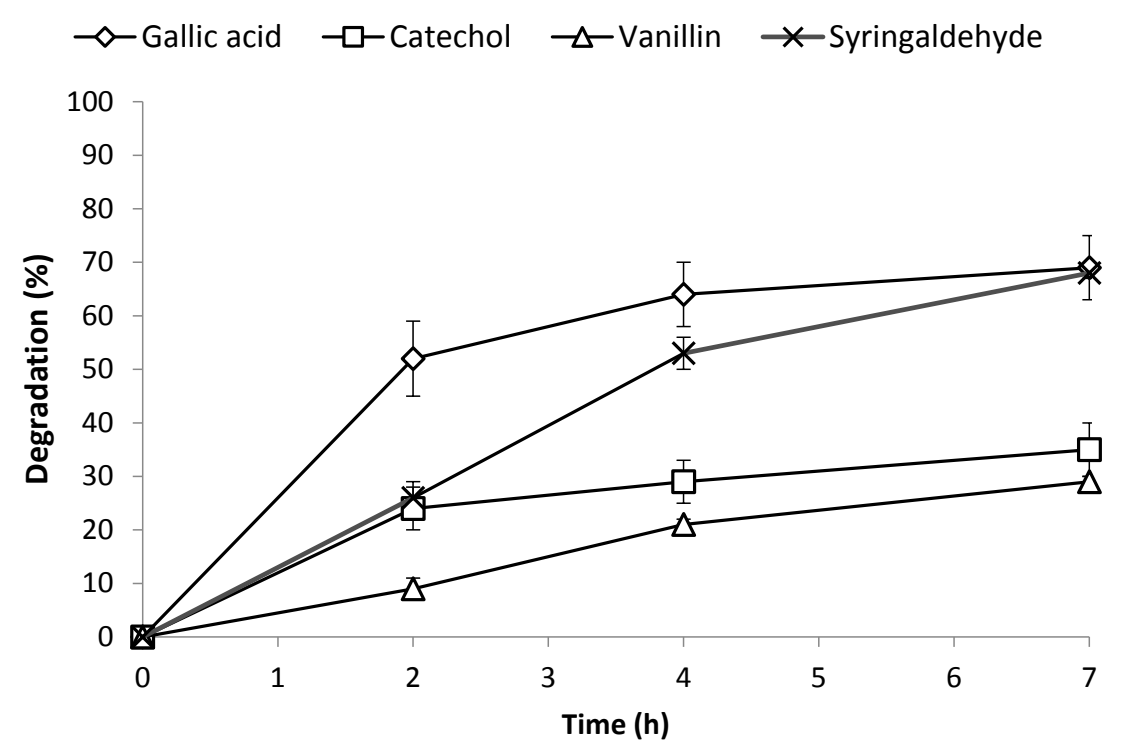

Figure 5. Degradation of the individual phenolic compounds using the liquid laccase enzyme as a function of time.

A sample with a predominance of gallic acid would be degraded faster than a sample rich in vanillin. It would be interesting to test the capacity of degradation on other type of phenolic compounds. On the other side, considering the variety of phenolic compounds, it is almost impossible to determine all individual efficiencies. Therefore, it is suggested to determine the group preference, as it is done with the alcohol group in this work.

\subsection{Influence of the Initial Phenolic Compounds Concentration}

To determine the capacity of laccase to degrade a concentrated mixture of phenolic compounds, their degradation at different initial concentrations was studied. At the same conditions and proportional dosage, there is a better degradation at the lowest initial concentration (Figure 6). With initial concentration of $2 \mathrm{~g} / \mathrm{L}$ of phenolic compounds, the degradation is $79 \%$, at $4 \mathrm{~g} / \mathrm{L}$ it drops to $55 \%$ and at $6 \mathrm{~g} / \mathrm{L}$ only $25 \%$ of the phenolic compounds are degraded by the solid laccase. It is important to point out that the increase of the dosage up to $200 \mathrm{mg} / \mathrm{g}$ of phenolic compounds can partially offset the increase of the initial concentration. Indeed, with $200 \mathrm{mg} / \mathrm{g}$ of phenolic compounds, the degradation reaches $38 \%$ with an initial phenolic compounds concentration of $6 \mathrm{~g} / \mathrm{L}$. It is $13 \%$ more than with only $100 \mathrm{mg} / \mathrm{g}$ of phenolic compounds. There is a link between the dosage and the efficiency at high concentrations of phenolic compounds. For the liquid laccase, an initial concentration of $2 \mathrm{~g} / \mathrm{L}$ of phenolic compounds allows a degradation of $25 \%$ (Figure 6). However, with $4 \mathrm{~g} / \mathrm{L}$, only $15 \%$ of the phenolic compounds are degraded and with $6 \mathrm{~g} / \mathrm{L}, 14 \%$. Regarding the liquid laccase, the difference between the results was due to an increase in the concentration of syringaldehyde, catechol and vanillin. It was difficult to degrade these compounds by the liquid laccase and the residual amount was higher than expected. For the solid laccase, a similar phenomenon occurs. Regardless of the initial concentration $(2,4$ or $6 \mathrm{~g} / \mathrm{L})$, gallic acid will always be degraded entirely in $2 \mathrm{~h}$. The catechol degradation is around 100\%, although it is slightly less effective when the initial concentration of the phenolic compounds increases to $6 \mathrm{~g} / \mathrm{L}$. The residual phenolics are vanillin and syringaldehyde. It seems to be difficult for the solid laccase to degrade those phenolic compounds at higher concentrations. 


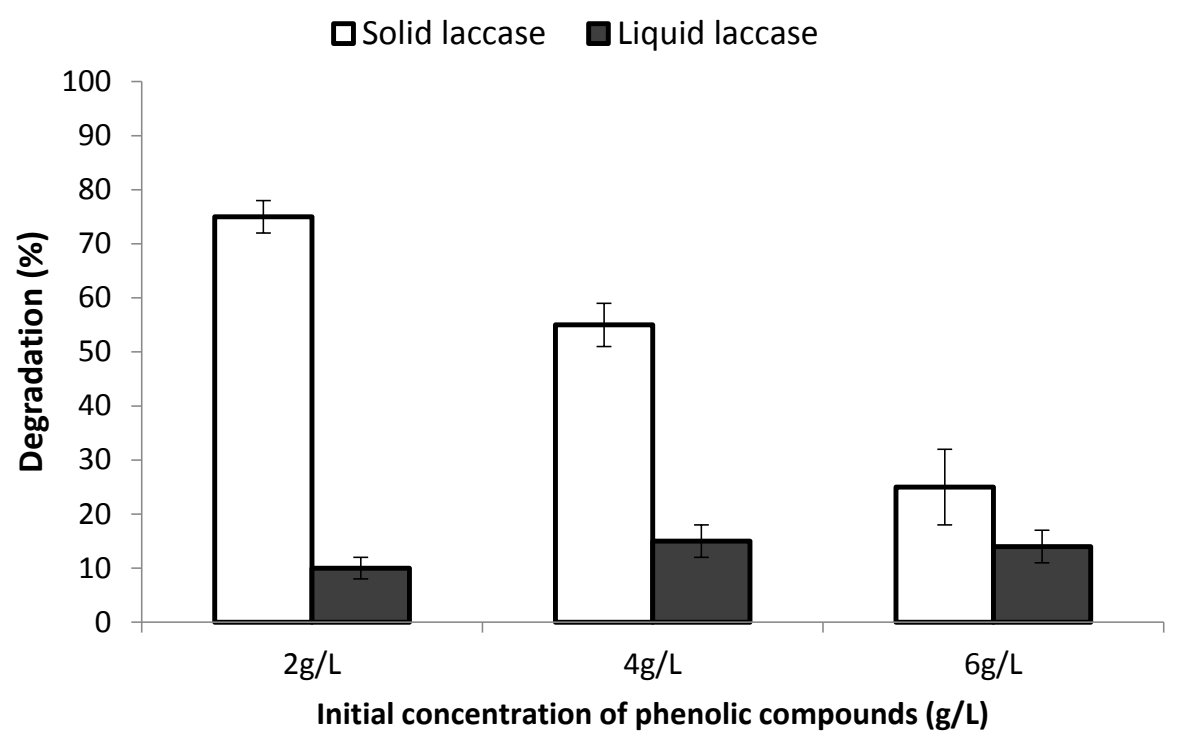

Figure 6. Degradation of the phenolic compounds by laccase enzymes as a function of the initial concentration of phenolic compounds.

\subsection{Hydrolysate Detoxification by Laccase}

Finally, the efficiency of the laccase enzymes on pre-hydrolysate samples pretreated with different detoxification methods were tested. As shown in Figure 7, the best degradation of the phenolic compounds occurs in the flocculated non-filtrated hydrolysate, and by the solid laccase, at its optimum conditions. In fact, this is the only case where laccase sufficiently degrades phenolic compounds to a concentration below the minimum level of inhibition determined by Mechmech et al. [9]. The level of degradation can reach a leftover of phenolic compounds of $0.28 \mathrm{~g} / \mathrm{L}$, under the limit of inhibition of ABE fermentation of $1.1 \mathrm{~g} / \mathrm{L}$ in flocculated media. However, none of the other samples can reach this limit or the limit of $0.3 \mathrm{~g} / \mathrm{L}$ for the non-flocculated sample. Theoretically, the percentage of degradation is expected to be similar from one sample to another, but in practice, the composition of each sample may vary significantly. For example, phenolic compounds proportion can be different between flocculated samples and untreated samples. The results show a significant difference in the degradation of the phenolic compounds for each intermediate stage of detoxification. However, there is a link between the enzyme type and the efficiency of detoxification by laccase at each intermediate stage (Figure 7). The liquid laccase seems to be more efficient when used before flocculation, with a degradation percentage of $42 \%$ for the untreated hydrolysate and $36 \%$, for the filtered hydrolysate. Two hypotheses are envisaged. First, it is possible that the flocculation removes mainly phenolic compounds that would also be degraded by the liquid laccase, thus reducing the total amount of initial phenolic compounds to be degraded. Then, the residual ferric sulfate used for flocculation can form a complex with the laccase, thus making the enzyme less effective or inactive. The solid laccase is very efficient on flocculated hydrolysate and less efficient on untreated hydrolysate. The hydrolysate composition is complex and may be the source of the variation in the effectiveness of the laccase enzymes. 


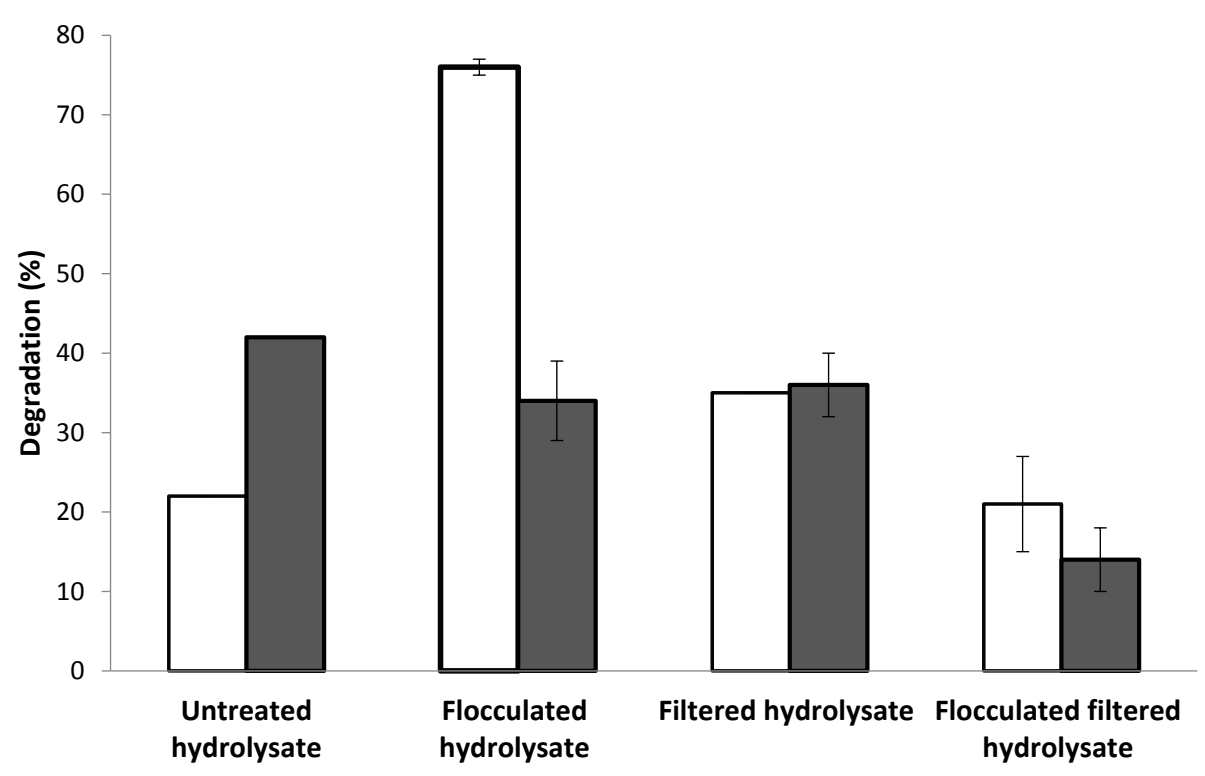

Figure 7. Degradation percentage of phenolic compounds by laccase enzymes in hydrolysates pre-treated by different methods. White: solid laccase; Black: liquid laccase.

\subsection{Impact of the Additional Degradation by Laccase on ABE Fermentation}

The production of butanol by C. acetobutylicum from a detoxified and not detoxified substrate by laccase enzymes was tested. In the case of the substrate detoxified by the solid enzyme, the production of butanol by C. acetobutylicum can double, compared with the substrate containing toxic phenolic compounds. The butanol production increases from $1.54 \mathrm{~g} / \mathrm{L}$ to $4.17 \mathrm{~g} / \mathrm{L}$. The results are homogeneous and indicate a clear trend on the effectiveness of the solid laccase. The detoxification by laccase enhances the efficiency of the ABE fermentation, by decreasing the concentration of the phenolic compounds under the limit of inhibition. In the case of the liquid laccase, no butanol production occurs. The reason for this outcome should be investigated, but a negative interaction between the bacteria and the enzyme, or its degradation products is suspected.

\section{Conclusions}

In this work, it has been shown that laccase enzymes efficiently degrade phenolic compounds in wood hydrolysates. At an optimum temperature of $50{ }^{\circ} \mathrm{C}, \mathrm{pH}$ of 8 and enzyme dose of $100 \mathrm{mg} / \mathrm{g}$ of phenolic compounds, the degradation of the phenolic compounds reaches $77 \%$. The use of laccase for wood hydrolysate detoxification reduces the phenolic compounds concentration to $0.28 \mathrm{~g} / \mathrm{L}$, far below the limit of inhibition. The hydrolysate detoxification combining flocculation and laccase enzymes prior to fermentation increases the amount of butanol produced.

Acknowledgments: This work was supported by a grant from the College-University I2I Program of the Natural Sciences and Engineering Research Council of Canada (grant number 437803-12) and BioFuelNet Canada, a Network of Centers of Excellence. The authors wish to express their gratitude to CNETE for hosting the experimental work, especially to Nathalie Martel and Louis Tessier for their help, to FPInnovations for supplying the pre-hydrolysate samples and to Fraunhofer and Metgen Oy for providing the enzyme samples.

Author Contributions: Rosalie Allard-Massicotte, Hassan Chadjaa and Mariya Marinova conceived and designed the experiments; Rosalie Allard-Massicotte performed the experiments; Rosalie Allard-Massicotte and Hassan Chadjaa analyzed the data; Hassan Chadjaa and Mariya Marinova contributed to reagents/materials/ analysis tools; Rosalie Allard-Massicotte and Mariya Marinova wrote the paper.

Conflicts of Interest: The authors declare no conflict of interest. 


\section{References}

1. Jones, D.T.; Woods, D.R. Acetone-butanol fermentation revisited. Microbiol. Rev. 1986, 50, 484-524.

2. Lee, S.Y.; Park, J.H.; Jang, S.H.; Nielsen, L.K.; Kim, J.; Jung, K.S. Fermentative butanol production by clostridia. Biotechnol. Bioeng. 2008, 101, 209-228. [CrossRef] [PubMed]

3. Kirschner, M. n-Butanol. Chem. Mark. Report. 2006, 269, 42.

4. Ajao, O.; LeHir, M.; Rahni, M.; Marinova, M.; Chadjaa, H.; Savadogo, O. Concentration and Detoxification of Kraft Prehydrolysate by Combining Nanofiltration with Flocculation. Ind. Eng. Chem. Res. 2015, 54, 1113-1122. [CrossRef]

5. Ajao, O.; Rahni, M.; Marinova, M.; Chadjaa, H.; Savadogo, O. Retention and flux characteristics of nanofiltration membranes during hemicellulose prehydrolysate concentration. Chem. Eng. J. 2015, 260, 605-615. [CrossRef]

6. Chandel, A.K.; da Silva, S.S.; Singh, O. V. Detoxification of Lignocellulose Hydrolysates: Biochemical and Metabolic Engineering Toward White Biotechnology. Bioenergy Res. 2013, 6, 388-401. [CrossRef]

7. Baral, N.R.; Shah, A. Microbial inhibitors: formation and effects on acetone-butanol-ethanol fermentation of lignocellulosic biomass. Appl. Microbiol. Biotechnol. 2014, 98, 9151-9172. [CrossRef] [PubMed]

8. Palmqvist, E.; Hahn-Hagerdal, B. Fermentation of lignocellulosic hydrolyzates. II: Inhibitors and mechanisms of inhibition. Bioresour. Technol. 2000, 74, 25-33. [CrossRef]

9. Mechmech, F.; Chadjaa, H.; Rahni, M.; Marinova, M.; Ben Akacha, N.; Gargouri, M. Improvement of butanol production from a hardwood hemicelluloses hydrolysate by combined sugar concentration and phenols removal. Bioresour. Technol. 2015, 192, 287-295. [CrossRef] [PubMed]

10. Madhavi, V.; Lele, S.S. Laccase: properties and applications. Bioresources 2009, 4, 1694-1717.

11. Wang, Z.X.; Cai, Y.J.; Liao, X.R.; Tao, G.J.; Li, Y.Y.; Zhang, F.; Zhang, D.B. Purification and characterization of two thermostable laccases with high cold adapted characteristics from Pycnoporus sp. SYBC-L1. Process Biochem. 2010, 45, 1720-1729. [CrossRef]

12. Sherif, M.; Waung, D.; Korbeci, B.; Mavisakalyan, V.; Flick, R.; Brown, G.; Abou-Zaid, M.; Yakunin, A.F.; Master, E.R. Biochemical studies of the multicopper oxidase (small laccase) from Streptomyces coelicolor using bioactive phytochemicals and site-directed mutagenesis. Microb. Biotechnol. 2013, 6, 588-597. [CrossRef] [PubMed]

13. Bayramoğlu, G.; Arica, M.Y. Enzymatic removal of phenol and p-chlorophenol in enzyme reactor: Horseradish peroxidase immobilized on magnetic beads. J. Hazard. Mater. 2008, 156, 148-155. [CrossRef] [PubMed]

14. Dasgupta, S.; Taylor, K.E.; Bewtra, J.K.; Biswas, N. Inactivation of enzyme laccase and role of cosubstrate oxygen in enzymatic removal of phenol from water. Water Environ. Res. 2007, 79, 858-867. [CrossRef] [PubMed]

15. Kauffmann, C.; Petersen, B.R.; Bjerrum, M.J. Enzymatic removal of phenols from aqueous solutions by Coprinus cinereus peroxidase and hydrogen peroxide. J. Biotechnol. 1999, 73, 71-74. [CrossRef]

16. Moreno, A.D.; Ibarra, D.; Fernandez, J.L.; Ballesteros, M. Different laccase detoxification strategies for ethanol production from lignocellulosic biomass by the thermotolerant yeast Kluyveromyces marxianus CECT 10875. Bioresour. Technol. 2012, 106, 101-109. [CrossRef] [PubMed]

17. Marinova, M.; Mateos-Espejel, E.; Jemaa, N.; Paris, J. Addressing the increased energy demand of a Kraft mill biorefinery: The hemicellulose extraction case. Chem. Eng. Res. Des. 2009, 87, 1269-1275. [CrossRef]

18. Singleton, V.L.; Rossi, J.A.J. Colorimetry of total phenolics with phosphomolybdic-phosphotungstic acid reagents. Am. J. Enol. Vitic. 1965, 16, 144-158.

(C) 2017 by the authors. Licensee MDPI, Basel, Switzerland. This article is an open access article distributed under the terms and conditions of the Creative Commons Attribution (CC BY) license (http:/ / creativecommons.org/licenses/by/4.0/). 